\title{
Lo que adviene al ser en ritmo
}

\author{
Victor Fuen-Mayor \\ Universidad del Zulia, Venezuela
}

\begin{abstract}
Resumen
En este ensayo filosófico, postulo que el ritmo no es solo cuestión del las artes sino también un elemento esencial para la investigación de la comunicación cultural en las ciencias humanas contemporáneas. Hago uso de una expresión antigua con raíz latina adventus para designar la aventura, el adviento, la venida de algo que llega con los significantes artísticos. A la continuación, trato de algunos tópicos relacionados con el ritmo, tales como, la rítmica de las imágenes, el ritmo y la función poética (JACOBSON, 1981), el cuerpo invisible que se hace visible, la idea de la dimensión invisible de la comunicación no verbal en las culturas, la profundidad emergente de un ser en ritmo, la rítmica anterior a los lenguajes: la cora semiótica (KRISTEVA, 1974), y aspectos de la escucha del ritmo. Al fin, concluyo que la ritmicidad es el principio conector entre lo biológico y lo simbólico de la vida.
\end{abstract}

Palabras-clave: ritmo, el ser en el ritmo, ritmo y cuerpo, ritmo en las artes.

\begin{abstract}
In this philosophical essay, I claim that rhythm is not only a matter of the arts but also an essential element to investigate cultural communication in contemporary human sciences. I use the old Latin-rooted expression adventus to designate adventure, advent, the forthcoming of something that arrives with the artistic signifiers. Following, I deal with some topics related to rhythm, such as, the rhythm of images, rhythm and poetic function (JACOBSON, 1981), the invisible body that becomes visible, the idea of the invisible dimension of the non-verbal communication in cultures, the emerging depth of a rhythmic being, the rhythm before languages: the semiotic cora (KRISTEVA, 1974), and aspects of the rhythm listening. Finally, I conclude that rhythmicity is the connecting principle between the biological and the symbolic of life.
\end{abstract}

Keywords: rhythm, the being in the rhythm, rhythm and body, rhythm in arts. 


\section{La aventura del ser en ritmo.}

El ritmo hace advenir algo de lo que soy en el origen corpóreo. Eso que soy en el inicio, antes de ser sujeto, consiste en una verdad rítmica del movimiento que se entreteje entre lo innato biológico y lo adquirido cultural. Las artes sitúan ese entrecruce entre la vida y la cultura, lo orgánico y la comunicación, y con mayor razón, el ritmo que aparece así al nacer, desde los primeros días de ser paridos, como efecto de una escucha corpórea cenestésica de la voz humana más que del solo órgano de la audición. Lo artístico contiene, a través del ritmo, una verdad corpórea en el límite de lo biológico-cultural y es la razón mayor del por qué las artes, las ciencias humanas y las pedagogías contemporáneas priorizan el cuerpo y el hecho artístico como modelo artístico, científico y pedagógico.

El ritmo, por ejemplo, no es solo cuestión del las artes escénicas sino también esencial para el objeto de la investigación de la comunicación cultural en las ciencias humanas contemporáneas. El ritmo nos acerca a esa verdad mayor de lo humano, antes de ser sujetos y conscientes, puesto que la fijación rítmica se hace previa a la adquisición de los lenguajes, de la cultura y de la construcción del sujeto y del objeto y sin el ritmo serían imposibles esas adquisiciones posteriores.

El ritmo situaría el origen corpóreo en un estado de pre-sujeto y de pre-objeto, en una marca originaria de la memoria biológica y energética, sin representación, opuesta a la memoria lingüística o semántica. Y eso que adviene en el arte a través del ritmo teje un velo de la verdad humana que, anterior a la palabra, se manifiesta en movimientos, imágenes y vocalizaciones anteriores a los sonidos de los signos de la lengua.

Esa es la aventura mayor del ser en ritmo: cuando el sujeto se deja llevar por esa adquisición tan antigua de inscripción de humanidad que se hunde en las determinaciones de fibras musculares y neurocerebrales para conformar la comunicación básica o primitiva que, inscribiendo la sincronía cultural de los seres humanos, forma parte de las construcciones en las artes.

\section{Lo que adviene con el ritmo}

Eso que le adviene al ser en ritmo me hace usar una voz antigua que, proveniente de la raíz latina adventus, designa con la misma raíz la aventura, el adviento, lo que viene, la venida de algo que llega con los significantes artísticos, en nuestro caso, no con los significados.

El ritmo puede ser una inducción a la creación que precede y acompaña al texto artístico a partir de lo que se desea que venga o que advenga. Desde los efectos inconscientes del trance o posesión con los ritmos en los rituales de las religiones afrocaribeñas a los movimientos de elaboración pictórica para provocar un estado físico especial, en nuestros artistas contemporáneos, que implican movimientos rítmicos en la creación pictórica: el catalán Antoni Tapies (Barcelona, 
1923-2012) con sus pasos al ritmo de tambores africanos antes de iniciar su faena pictórica ${ }^{1}$, en el chino-venezolano Francisco Hung (Cantón 1937- Maracaibo 2001) con pasos y gritos de artes marciales orientales mientras pintaba; el artista venezolano Armando Reverón (Caracas, 18891954) con su ritual tauromáquico con efectos de trance o de sueño diurno autoinducidos a través del ritmo durante la realización pictórica ${ }^{2}$.

¿Qué es lo que acontece en cuerpo como efecto ante esos ritmos que inducen la creación más allá de las artes vivientes o escénicas? Las palabras castellanas adviento, advenimiento y aventura están relacionadas con la misma raíz latina: adventus. El adviento artístico forma parte de ese proceso de buscar, a través del ritmo, las formas significantes de expresión en relación a la verdad primera, en esa espera de conexión actual con un acontecer corpóreo y pre-expresivo que implica el retorno de un recuerdo del cuerpo originario, preverbal, perdido u olvidado, que el ritmo puede rescatar y traer al presente en conexión con signicantes de los lenguajes artísticos actuales.

Esas voces etimológicas latinas del adviento celebran el retorno corpóreo y nombran también el misterio del cuerpo resucitado que retorna glorioso de la muerte. Lo que adviene a través del ritmo artístico tiene que ver con ese misterio del retorno corpóreo de una poética rítmica de la memoria Construyendo el significante rítmico del recuerdo con la aventura artística de la materialidad de los lenguajes artísticos, aparece de manera extraña e inconsciente, como en sueños (así pensaba el artista venezolano Armando Reverón cuando aparecía la imagen a partir de los movimientos rítmicos).

El adviento sacude al cuerpo rítmico del origen en el ahora de un presente y otorga originalidad textual a través de lo que viene del pasado, antes de la consciencia y de la razón, es decir inconscientemente, junto con la materialidad significante que influye en la construcción de la originalidad de las formas.

La energía determina la impresión rítmica de afectos en las fibras neuromusculares de un cuerpo originario que marcará con la intensidad de la variación energética los significantes memorables de los acontecimientos de la infancia. Las formas rítmicas de originalidad en la creación y en la lectura me hacen lanzar una pregunta que concierne al ser en ritmo: ¿Qué adviene a

\footnotetext{
${ }^{1}$ Il existe des moyens naturels pour estimuler l' imagination, pour exciter l'imagination, bref pour préparer au travail. J'ai fait une expérience des bons resultats que je pouvvais obtenir d'une marche rythmique, acompagnées des sons rythmés, autour de mon atelier. C doit etre quelques chose d'assez voisins du type d'excitations que procurent les dances africaines. (TAPIES, Antoni, 1971 La pratique de l'art,p. 98)

${ }^{2}$ Es como un sueño en el que no sabes por qué asi suceden las cosas. La pintura es igual. "Visto por si mismo, Entrevista, Apuntes tomados por nuestro reportero Carlos Morantes, Diario El Nacional (16/03/1953), en ELDERFIELD, John y otros, Armando Reverón, 227).
} 
través del ritmo cuando realiza un proceso de creación y qué adviene al lector de los textos cuando encuentra ritmo de la lectura que se ajusta a la escritura?

Cuando se trata de solo leer los significados textuales, el ritmo puede ser ignorado; pero no puede ignorarse cuando se trata en semiología textual de explicar las determinaciones de las formas significantes o de sus determinaciones oníricas. En el psicoanálisis, semiología, kinésica, proxémica no puede ser ignorado la expresión rítmica en la lectura, puesto que marca la presencia más fuerte o energizada de ciertos aspectos textuales en relación con los de intensidad menor o más débiles o inertes. No todos los elementos del texto artístico tienen un mismo valor y el ritmo nos lleva a considerar las intensidades entre los significantes artísticos que mantienen el eje de los sentidos posibles.

Esos trazos significantes, que están determinados por el ritmo, la energía y el afecto, nos hacen sospechar la presencia de una huella de la corporeidad primera o primitiva marcando la intensidad actual de los significantes en el espacio-temporalidad del ritmo textual.

\section{El cuerpo invisible}

No es fácil responder sobre lo que adviene a través del ritmo cuya inscripción es tan antigua y que se pierde en el origen de la vida, puesto que no se trata solo de lo corpóreo en las artes escénicas o vivientes, donde el cuerpo viviente se exhibe como presencia visible en la escena, sino que me refiero a todas las expresiones artísticas cuya corporeidad no es evidente en un cuerpo presente y visible sino a través de lo que transfiere o extiende a las marcas rítmicas en las imágenes de los lenguajes pueden materializarlo y que llegan a construir lo que las palabras impliquen en significar, de manera indirecta, otras cosas que las dichas o escritas en las palabras con signos ocultos en extensiones rítmicas corpóreas de juegos anagramáticos y aliteraciones. ${ }^{3}$

La lectura significante de la textualidad artística puede articular un nombre cuerpo, de un dios o del propio autor que no está escrito en ninguna palabra del texto sino en las conexiones entre significantes textuales. Es una segunda manera de ser del signo, sin significado evidente, sino en las conexiones de una red significante de sonidos repercutidos, de imágenes, repetidos por ritmos métricos cuyas huellas vehiculan parasitariamente las letras del nombre-cuerpo o de un dios. También las materialidades significantes en los textos pictóricos pueden remitir a anagratismos

\footnotetext{
${ }^{3}$ EL ANAGRAMATISMO podría ser común a las artes, aunque se hace más evidente en la espacialidad literaria y poética. Pudiera ser una de esas formas que, en la contemporaneidad, participe en la formulación más precisa de una metodología para analizar el código de contacto entre los textos corporales, visuales y literarios. (...)Lo que emplea Tapies para hacer poesía visual traduce bien los procesos anagramáticos de la escritura literaria al espacio de la plástica: dispersión de letras en un texto para esconder el nombre, tal como había formulado Saussure en sus Anagramas. (FUENMAYOR, Víctor, 1999, El cuerpo de la obra, p. 343).
} 
visuales como en los poemas visuales de Antoni Tapies ${ }^{4}$ donde las letras de su nombre se encuentran dispersas en varios textos de su estética matérica, pictórica y literaria. Podemos señalar, en esas creaciones, su contenido integrativo de cuerpo, plástica y escritura donde la corporeidad se encuentra en el punto de cruce de los significantes entre varios lenguajes.

Esa corporeidad tejida con elementos de varias expresiones (corpóreas, visuales y literarias) nos lleva contradictoriamente a la invisibilidad del cuerpo transpuesto en las materias artísticas. Esa dificultad de conocer las determinaciones corpóreas hace que las ciencias humanas, aún en los cuerpos visibles de las artes escénicas, investiguen bajo qué forma musical o coreográfica el texto implica la corporeidad del actor-bailarín-intérprete para revelar las determinaciones culturales de los significantes que hacen visible el cuerpo ritmado y modelado por códigos inconscientes de las partituras artísticas que fundan la cultura.

No es lo mismo ver danzar los cuerpos de la norteamericana Katherine Dunhan, afroamericanos formados en la técnica de la expresión primitiva derivado de las técnicas tradicionales caribeñas, que los bailarines de ballet cubano formados por Alicia Alonso con las técnicas balletísticas rusas, aunque estén bailando música popular o caribeña. El dejarse llevar el cuerpo por el ritmo no forma parte de la tradición de los cuerpos tecnificados a través del ballet clásico.

¿Qué se hace visible en los cuerpos tecnificados? Veremos que los cuerpos movidos por los ritmos son corporeidades cuyo origen encuentra su expresión en la vida cotidiana y en los movimientos de la escena; mientras que las danzas movidas por técnicas balletísticas, menos rítmicas (con predominio melódico) y en punta, adoptando esa separación del pié a la tierra para constituir un modelo etéreo de un cuerpo, sin raíz, que niega la gravedad de la tierra y de su origen. Las técnicas rítmicas (flamenco, danzas africanas, afroamericanas y precolombinas) priorizan el uso de los talones y golpes rítmicos a la tierra, afirmando con esa tradición cultural el ritmo como un reconocimiento a la materialidad corpórea, originaria y terrenal de la vida humana cuando se enraíza en una cultura predominantemente rítmica.

\section{El cuerpo invisible que se hace visible}

La idea de la dimensión invisible de la comunicación no verbal en las culturas proviene de la investigación del ritmo en las artes y en la comunicación cultural. La cultura primaria, esencial o primitiva (llamada así por los autores anglo-americanos de la dimensión invisible: Edward T. Hall, Birdwhistell, Bateson y otros), sigue las técnicas rítmicas de la cultura, las coreografías culturales

\footnotetext{
${ }^{4}$ Ver “Las palabras de un cuerpo: ¿En qué lengua se pinta?”, en: FUENMAYOR, Víctor, 1999, El cuerpo de la obra, p.p. 333 y siguientes. 
de la comunicación no verbal que organizan las orquestaciones y partituras espontáneas de individuos de una misma cultura o de códigos intertextuales de culturas en contacto.

Las ciencias humanas contemporáneas están sembradas de ritmos artísticos que fundamentan las teorías con testimonios visuales (fotográficos, videográficos y cinematográficos) de la kinésica, proxémica y rítmica de las sociedades o grupos sociales, para revelar el modelo kinésico, proxémico y rítmico de un cuerpo invisible que determina las acciones, conductas y comportamientos de los individuos y grupos en una misma cultura o de culturas en contacto. La invisibilidad de la corporeidad proviene desde un cuerpo en la escena lejana, originaria, inasible, una marca de nacimiento que deja huella en una interiorización rítmica fijada en una gramática inconsciente y corpórea y que nos humaniza y semiotiza en todos los tipos de comunicaciones y expresiones. La invisibilidad corpórea que ellos investigan se origina en un espacio cultural no verbal cuya ley de construcción es artística o coreográfico-musical: espacios cotidianos de las ciudades donde los investigadores de la semiótica, proxémica, kinésica, encuentran testimonios rítmicos de las orquestaciones, partituras, coreografías y danzas de la vida. Recuerden el método de Pina Bausch: mandaba a los bailarines a recorrer las ciudades donde llegaban para seleccionar los movimientos que podían ser parte de las coreografías que las autoridades habían solicitado de la coreógrafa. Así la coreógrafa Bausch se basaba en la percepción de las coreografías culturales percibidas por la investigación in situ de los bailarines. El método artístico hace eco del método científico. El imaginario del arte se convierte en herramientas de las ciencias sin perder su cientificidad.

Esas investigaciones de la escena social del cuerpo invisible tiene la implicación en la invisibilidad del cuerpo de los actores en el teatro. Desde la experiencia del teatro griego, la escena (skéné) era el lugar invisible a los ojos de los espectadores donde los actores se ponían las máscaras, antes de salir al proscenio que estaba cerca de los espectadores. La escena no era el escenario actual sino una construcción provisional (choza, barraca, pabellón, tienda de campaña), donde los actores preparaban la salida al proscenio). La metáfora engendra el sustantivo masculino (skénos) que es el cuerpo humano en tanto que aloja temporalmente al alma ${ }^{5}$. Aceptemos esos términos metafóricos en que el cuerpo visible del proscenio implica una corporeidad invisible donde el actor se prepara, se viste y desviste, se quita y se coloca las máscaras. Ese lugar de la invisibilidad del cuerpo preparándose para la salida a la escena revela la metáfora científica de nuestros contemporáneos: los preparativos de la escena inconsciente apoyados en los ritmos del origen como conexión entre el

\footnotetext{
5 PRADIER, Jean-Marie (1996), “Ethno-scénologie: Le profondeur des emergences”, en La scéne et la terre. Questions d' ethnoscénologie, p.14). 
estilo individual y las tradiciones culturales, donde los ritmos pueden revelar los códigos determinantes de la construcción del cuerpo cultural que revelarían la implicación corpóreo en los significantes artísticos. El significante rítmico es como el ropaje que anuncia el indicio de que existe un cuerpo invisible que debe hacerse visible de acuerdo a las determinaciones de los significantes: cómo se mueve, cuáles son los gestos, a qué ritmo, que pueden llevarnos a una identificación que visibiliza el modelo inconsciente que domina su actuación.

Los ritmos pueden ser los inductores de la emergencia de las representaciones artísticas o culturales de ese cuerpo invisible de la escena originaria e inconsciente y que reaparece en forma oculta bajo las determinaciones de los significantes actuales que emergen como indicios visibles de lo corpóreo en el texto artístico, marcando con sus huellas la materialidad de los lenguajes. Para dar un ejemplo simple: no podemos hablar sin cuerpo, sin que el acento de ese ritmo significante con que hablamos nos delate el origen de la "originalidad" hablante que matiza el habla porteña, argentina o venezolana. Y aunque seamos hablantes de una misma lengua, el ritmo delata cuerpo de origen en la originalidad del estilo como la matización individual de los códigos culturales y de las conexiones corpóreas con nuestro origen.

Se trata de situar a través del ritmo, una marca corpórea de originalidad que nos haga visualizar el cuerpo invisible y originario, de encarnación de los determinantes simbólicos en nuestro cuerpo con que vive el ser en ritmo vive y marca el espacio artístico a través de la escena inconsciente. La creación se mueve al ritmo del cuerpo invisible y marca con huellas corpóreas la materialidad de los textos. La escena corpórea, visual o literaria sitúa el tiempo y los espacios interiorizados que los textos artísticos dejan percibir y que deben repercutir en la percepción de los espectadores y lectores como conexión sensible e inconsciente. Los sentidos perspicaces de los investigadores en ciencias humanas saben detectar los pasos rítmicos del cuerpo en los textos artísticos.

\section{La profundidad emergente de un ser en ritmo}

Ese cuerpo invisible e invisible que emerge del ritmo en el arte tiene una escucha que lo haga visible en sus códigos, leyes o determinaciones. Todas las percepciones de la textualidad deben llevarse a entender los procesos de creación de la red de significantes y de la lectura de acuerdo a una de las ciencias humanas que estudia tanto los signos en la vida social, como las determinaciones inconscientes de los códigos culturales bajo formas orquestales y coreográficas de la comunicación cultural.

La presencia viva en las artes se encuentra en las leyes de la escena inconsciente, individual y cultural, como la prolongación o extensión de los cuerpos en las representaciones escénicas, 
pictóricas o literarias. El ritmo toca la sensibilidad del cuerpo moviente, de la energía kinésica y de la emocionalidad para crear un espacio vinculante entre actores y espectadores, entre lectores y escritores, entre individuos de una misma cultura o en el contacto con los otros individuos de otras culturas. Es como si las leyes del arte extendieran el ser en ritmo que es la humanidad a la cultura básica, corpórea, no verbal o primitiva, de cualquiera de las culturas. Esa emocionalidad del sentir el arte puede percibirse, encontrarse y leerse en una definición metodológica que justificaría la pregunta del inicio sobre lo que adviene con el ritmo en boca de un muy reconocido semiólogo francés: ¿Qué es, entonces, para mí, la semiología? Es una aventura, es decir, lo que me adviene (lo que me viene del significante).(BARTHES, 1990, p.10).

La aventura del artista implica, como para el lector semiólogo, la emergencia corpórea del ser en ritmo y debe implicar la aventura del toque que recibe el lector o espectador a través de las redes significantes del texto artístico. El proceso de crear arte comprende la emergencia, consciente o inconsciente, de procedimientos artísticos para hacer advenir los sentidos corpóreos al ritmar las líneas, rimar las formas, llegar a la métrica visible que revele el invisible cuerpo que determina los colores, los gestos o movimientos. El ritmo es la escucha que revela el nombre cuerpo entre las aliteraciones del poema, de las líneas y formas de la pintura, de los gestos y movimientos de la escena.

Los significantes en las diversas materialidades artísticas reciben la energía corpórea que induce el ritmo para aposentarse en el texto. Al ser cuerpo invisible, pero sensible a la percepción, formaría parte de procesos de vivencias de la creación y de escucha significante en la lectura que se saldrían de la estrechez de ciertos estudios lingüísticos y semiológicos tradicionales para abarcar la escena viviente de las artes y de las culturas. El arte expresa lo que acontece a niveles de la percepción sensorial rítmica de lo íntimo y de la singularidad, de los diferentes ritmos coreográficos en la comunicación cultural y de los principios transculturales del ritmo en todas las artes y en todas las culturas.

Si el ritmo de las artes puede llevarse al punto principial humano del origen en la construcción de humanidad y de la corporeidad cultural de la especie es porque el cuerpo biológico se apoya en la poética rítmica como una anterioridad expresiva de la precoz autoconstrucción poética o autopoiesis del ser humano que postula el cuerpo como espacio de un simbolismo natural o biológico del cuerpo humano en etapas originarias, pre-lingüísticas y pre-expresivas, anteriores a la adquisición de la lengua y de los lenguajes artísticos. Aunque es necesario reconocer que una vez adquiridos la lengua y los lenguajes, los procesos rítmicos apoyan la construcción de los juegos significantes de los lenguajes que se juegan entre una necesidad biológica del ritmo y la elaboración 
de la función poética de los significantes de los lenguajes culturales a través de la elaboración de las construcciones simbólicas.

No podemos llegar a adquirir y dominar la lengua materna con la que nos comunicamos sin pasar por las etapas kinésicas del ritmo vocálico del infante, de sonidos fluidos musicales de la etapa glosolálica del niño, que ya se parecen a la elaboración rítmica de la función poética de la lengua, a partir de los primeros significantes fijados en la escena primera de los aprendizajes. Existe una zona orgánica, biológica y poética del ritmo de los lenguajes artísticos que será necesario investigar como el espacio donde el ritmo precede o antecede a todas las adquisiciones posteriores lingüísticas y artísticas.

Podemos señalar dos etapas rítmicas que dependen se implican mutuamente, pero que se diferencian en el origen innato y biológico, previo a los signos y símbolos, y está el otro ritmo, también corpóreo, pero que debe afinarse en el contacto con los textos culturales. Ambos ritmos forman la creación subjetiva y artística de todos los lenguajes con que se expresará el sujeto en todos los lenguajes artísticos.

\title{
La rítmica anterior a los lenguajes: la Cora semiótica
}

El término de cora semiótica comprende el ritmo como primera organización semiótica del cuerpo biológico cuyo concepto proviene del Timeo de Platón para designar:

\begin{abstract}
Una articulación provisional, esencialmente móvil, constituida de movimientos y de sus detenimientos efimeros. (...) La cora en ella misma en tanto que ruptura y articulaciones-ritmo- es previa a la evidencia, a la verosimilitud, a la espacialidad y a la temporalidad. Nuestro discurso- el discurso- se encamina contra ella, es decir se apoya en ella y al mismo tiempo la rechaza, de manera que podemos situarla, en caso extremo prestar una topología, pero jamás axiomatizarla. (...). Ni modelo ni copia, ella es anterior y subyacente a la figuración entonces a la especularización, y no tolera más que analogías que con los ritmos vocales y kinésicos. (KRISTEVA, 1974, p. 23).
\end{abstract}

Podemos señalar que la cora semiótica es un proceso continuo, es un movimiento que solo se detiene por momentos. El niño se mueve sin cesar y apoyando en ese movimiento de la Cora se va instalando el ritmo cultura a partir de los sonidos de la voz de la madre. Esa atención al otro cuerpo va permitiendo el paso del ritmo de la Cora a la estabilización neuronal y al ingreso a la coreografía cultural.

Las primeras marcas de construcción afectiva del pre-sujeto y del pre-objetó se hacen a partir de la fijación de ritmos corpóreos en relación a los vínculos afectivos parentales que darán una permanencia rítmica según el temperamento inicial del niño, de manera en que el afecto vinculante construye las líneas rítmicas de la corporeidad del recién nacido. 
La Cora semiótica se llama con el mismo nombre que un cuento de Cortázar. La señorita Cora del cuento tiene que ver con el concepto de la Cora semiótica de Kristeva: se trata de separar algo del cuerpo, ese algo es también la separación con la madre, pero se trata de una cora desplazada a la adolescencia y de un órgano llamado el apéndice. La Cora semiótica necesita de un corte para que esa cortadura permita el salto tético, como la llama Kristeva, al ingreso del orden simbólico y de los signos. El adolescente hospitalizado que sufrirá una cirugía del apéndice es como una metáfora de esos cortes y separaciones.

El ritmo está implicado en el dinamismo del cuerpo biológico que encuentra en el ritmo cultural la base subyacente de la primera organización corpórea de las pulsiones, sin todavía tener consciencia del cuerpo, puesto que es previa a la constitución de la sincronización corpórea y de la construcción de los significantes de los lenguajes.

\section{La rítmica de las imágenes}

El ritmo forma parte de la satisfacción de una necesidad biológica esencial y originaria de la comunicación y de una sincronización con los otros cuerpos de la misma afiliación cultural. Existe como un desplazamiento del ritmo en que sigue el itinerario desde el ritmo de la cora semiótica, al ritmo del imaginario visual y luego al ritmo de la palabra.

El ritmo seguirá siendo cuerpo biológico y formará parte de los elementos de los lenguajes simbólicos que lo irán transformado en sus registros de materialidad, donde el pensamiento visual viene a desplazar el cuerpo rítmico como instrumento de comunicación a las representaciones visuales que estaban en estado naciente en la cora semiótica: Ni modelo ni copia, ella es anterior y subyacente a la figuración entonces a la especularización, y no tolera más que analogías que con los ritmos vocales y kinésicos. (KRISTEVA, 1974, p. 23).

Estamos en ese preludio de un ritmo que es cuerpo kinésico, imagen visual y ritmo vocal. Y me interesa señalar la insistencia de que el ritmo no es modelo ni copia sino lo que se inscribe en el imaginario está soportado por el ritmo que subyace a la figuración y especularización.

La figuración no es representación mimética ni lo que se conoce como arte figurativo sino que es una representación deformada por los afectos que afectan la imagen o la figuración. Es como si la imagen estuviera contaminada de afecto, no representando simplemente sino induciendo lo que le adviene al sujeto creador y al lector. Tenemos que pensar que la figuración es un término usado por Barthes opuesto a la representación mimética donde el afecto está representado pero no induce nada emocional. El ritmo de la figuración hace entrar la imagen en un proceso entre el lenguaje y la emocionalidad. 
Respecto al otro efecto del ritmo como es la especularización supone el concepto psicoanalítico lacaniano del estadio del espejo en esa percepción de dualidad o duplicación o multiplicación de las imágenes especulares, como los propios ritmos surgen de la repetición visual de considerar la preparación del reconocimiento de dos cuerpos que aparecen en el espejo o reiteración de los mismos elementos en las imágenes donde el infante entre 6 y 18 meses sigue la evolución de verse como "apéndice de su madre" a proyectar en la imagen del espejo la prefiguración de su yo en formación.

Y aquí quiero que reúnan las imágenes fotográficas de Alfredo Boulton para que vean el ritual corpóreo donde aparece el artista Armando Reverón haciendo su ritual de realización pictórica de una tauromaquia plástica en relación a los actos simbólicos corpóreos que dan resultado, en muchas de sus obras, de una duplicación de imágenes o de multiplicación de imágenes. Cito primero a Alfredo Boulton para que escuchen su percepción del ritual desde lo emocional y sexual, antes de pasar a mirar las figuraciones del inicio del estilo reveroniano:

Era un ejercicio extremadamente libre y sutil durante el cual las formas cobraban vida en la medida que el movimiento de su cuerpo mantenía su ritmo. Era una gesticulación que sugería reminiscencias de tipo erótico y como ancestral ante la presencia de un toro, tan constantes en algunos pintores ibéricos, y que en el ímpetu con que Reverón embestía el lienzo pudieran significar una velada intención sexual. (...) ...me llamó la atención el sentido, el ritmo de algunos gestos que tenían como reminiscencias "toreras" y que resultaban del impulso del cuerpo desnudo -vibraciones como de espasmos, como un prolongado orgasmo -cuando el artista se movía ante la obra. (BOULTON, 1966, p. 62).

El ritual contiene el movimiento rítmico del cuerpo de un erotismo cuyo sentido sexual es puesto en evidencia en el texto de la descripción, aunque no así en el texto fotográfico. Las formas rítmicas corpóreas de las vibraciones, espasmos, orgasmo, deben marcar los trazos de la tela y los contenidos.

Me referiré a dos épocas de la época inicial del estilo donde aparece la reduplicación especular donde el mismo artista Reverón aparece dos veces representado de niño y de adolescente en Retrato de familia (1919) y podemos comparar con Mujeres en la cueva (1919) donde aparecen dos mujeres misteriosas inmersas en una atmósfera de cueva marina de color azulado. En ambas obras iniciales del estilo, pintadas en el mismo año, aparece el mismo procedimiento de la duplicación especular y en una de ellas aparece la figuración en ese agregado de erotismo que va desde el señalamiento de los senos por una de ellas hasta la manera onírica de una materia sobada o como un esmalte con una gran imprecisión de las imágenes. 
Se diría que Reverón sitúa su pintura del lado del performance tauromáquico con los ritmos corpóreos relacionados con el erotismo de las acciones pictóricas donde el pincel sigue los trazos rítmicos de movimientos eróticos y de los sónicos vocálicos, bufidos, sin articular palabras. Las imágenes pictóricas, como en el caso reveroniano, tienen su ritmo corpóreo y musical que repercute en los trazos significantes y en el estilo de imágenes de la figuración velada e imprecisa y de la duplicación o multiplicación rítmica de una misma imagen que hace pensar en las formas oníricas. Se trataría de los ritmos oníricos del imaginario que comprendería la conexión entre el el estado especial que le adviene al cuerpo del artista y la elaboración de la figuración de la imagen.

\section{El ritmo y la función poética}

Cuando hablamos de función poética hacemos ingresar el lenguaje en los ritmos de las imágenes significantes (sonoras o gráficas) de las palabras. Se trata de un trabajo de elaboración de la materialidad del lenguaje que comprende repetición de letras, sílabas o sonidos para articular un significante en la escucha de sentido que no aparece ni escrito ni proferido en ningún lugar del texto. Entre las seis funciones básicas de la comunicación verbal: referencial, emotiva, conativa, fática, metalingüística y poética, se trataría de buscar el rasgo inherente y Roman Jacobson acota que se trata de una relación entre sonido y sentido. Y este mismo lingüista advierte que la función poética no se limita al campo de la poesía y se amplía al campo del lenguaje. De esa manera propone un lema político de una campaña presidencial norteamericana: I like Ike (ay layk ayk). Se trata de una rima en eco cuya aliteración ofrece una imagen paronomástica (palabras similares pero con distinto significado), la imagen paronomástica del sujeto amoroso envuelta por el objeto amado. La definición que da Jacobson de la función poética cubre una semántica de las artes debo llevar la escueta definición del lingüista sobre la función poética:

La tendencia hacia el MENSAJE como tal (Einstellung) es la función poética, que no puede estudiarse con efectividad si se aparta de los problemas generales del lenguaje, o por otra parte, el análisis de éste requiere una consideración profunda de su función poética. (JACOBSON, 1981, p.37) ${ }^{6}$

El ritmo es un contacto que emerge en la materialidad de los significantes de los lenguajes, antes de pasar por la consciencia. Más que de los significados, el ritmo condensa en una síntesis una implicación de la primera comunicación no verbal, cuerpo a cuerpo entre la madre y el niño cuyo ritmo vocal afectará los movimientos del infante desde el primero o segundo día de nacido. Primero seguirá la sincronización con cualquier voz y cualquier lengua, luego solo a los sonidos de la lengua

\footnotetext{
${ }^{6}$ El problema del cuerpo y los lenguajes es llevado a la relación de signos y objetos: También sirve para profundizar la dicotomía fundamental de signos y objetos, a base de promover la cualidad evidente de aquellos (Cf: JACOBSON, 1981, p.38)
} 
materna. El ritmo ocuparía el lugar de un cuerpo: el de la madre de la madre que se irá retirando y separando del niño en la medida que el aprendizaje de la lengua producirá el corte de la comunicación cuerpo a cuerpo para pasar a la comunicación por la palabra.

El ritmo es el intermediario de ese paso de la comunicación corpórea al orden simbólico. El espacio que ocupaba el cuerpo de la madre será ocupado por la lengua llamada materna cuya abstracción de los signos se hará haciendo poco a poco y no llegará a borrar la dependencia al cordón umbilical simbólico que será el ritmo y los efectos reactivos: el tono muscular, los vínculos afectivos que irradian los ritmos, el material de imágenes de los sueños. El ritmo, la repetición de letras de los murmullos lingüísticos en los sueños, la partitura personal que llevamos internamente y con la que nos movemos dentro de la coreografía cultural en que vivimos, forman parte de esos modelos rítmicos de comunicación íntima e interna que se condensan en las acciones y expresiones del ser en ritmo.

Los procesos rítmicos implican la biología del humano desde las primeras acciones para mantener la vida del cuerpo viviente. Desde un primer deseo oral que nace del amamantamiento, hasta la necesidad de reaccionar kinésicamente a la voz que le habla como primera comunicación rítmica los ritmos van tomando espacios del acuerpo a la imagen y de allí a la lengua.

\section{Abandono y retorno al ritmo}

El metro rítmico exige un abandono y una vuelta al dominio del lenguaje de donde emerge una interpretación del amor sentido y sublimado, una vez que debe volver a manifestarse bajo las formas rítmicas del arte. De acuerdo a lo que dice el Diccionario de Autoridades, esas transformaciones de los significantes de lenguajes a través del ritmo obedecen a una interpretación del amor o del deseo.

La cuestión del amor o el deseo atraviesa el ritmo de los textos en todos los lenguajes a través de las redes tejidas en la materialidad significante, de la elaboración o trabajo poética de la materialidad. Eso plantearía la lectura del enigma de la textualidad artística como una métrica del amor, como un arte matemáticamente humano, antes de la lógica del sentido y de la consciencia, que rara vez se toma en cuenta a la hora de la interpretación textual.

La cifra rítmica mueve las inscripciones neuromusculares más antiguas de significantes de recuerdos de acontecimientos inscritos en el cuerpo y que reactivan las energías de las fuerzas creativas a la escucha primitiva de ese ritmo interior que puede exteriorizarse inconscientemente en la materia de textualidad artística: cuerpo, imágenes o escrituras.

Las experiencias de Condon con los bebés recién nacidos nos indican que excitados por la voz llegan a seguir los ritmos de todas las lenguas, pero luego sólo los sonidos de la lengua 
materna. Eso indica que el cuerpo y el ritmo está estrechamente vinculados con los sonidos de la lengua desde el origen. Según las investigaciones, atestiguadas por filmaciones, la sincronización rítmica es innata y puede estar establecida al segundo día de la vida. Al principio seguirán el ritmo de cualquier lengua con movimientos del cuerpo, luego a los días siguientes lo hará con la lengua materna. Eso indica que la sincronización rítmica es un fenómeno innato según las experiencias investigadas por Condon. El ser en ritmo es cuerpo y es música donde el texto artístico aparecerá como un hallazgo. El ritmo no se busca sino que se encuentra y el cuerpo viene a él, aunque no quiera la consciencia, como parte de su ser.

El ritmo es un trazo, una marca primitiva o primera, interiorizado a niveles de determinaciones inconscientes. El ritmo es como el sentido del mito de Prometeo encadenado que podemos llamar Prometeo ritmado puesto que debe repetir el mismo acto con la roca, porque robó el fuego del sol para liberar a los hombres en que los temía sometido Zeus.

El ritmo tiene algo de liberador y contiene la roca y el fuego robado de Prometeo en nuestro encadenamiento rítmico que nos permite la libertad del arte. Y la acción artística se funda en esa libertad del ritmo que nos determina las formas artísticas que nos pertenecen en la esencia de lo humano, en nuestro ser y que puedan ser liberadoras y catárticas en las elaboraciones poéticas. Es como el primer signo con el que se armonizan los instrumentos antes de encontrar la melodía propia de nuestra existencia.

En cierto sentido, la nueva luz sobre la sincronización del hombre revela que las relaciones del hombre con todas las formas artísticas son mucho más íntimas de lo que generalmente se supone: el hombre es arte y viceversa. No hay manera de separar estas dos entidades. (...) Si bien todo lo que el hombre es y hace tiene significación, los ritmos y la sincronización del tipo que he descrito están clasificados como cosas que tienen poca importancia en Occidente. (HALL, 1978, p.76).

Que el hombre es arte y el arte es hombre, hace asumir el sentido pleno de humanidad del artista cuando se enfoca como un ser en ritmo afirmando esos dos conceptos del autor. El hombre es ritmo y sincronización como es el arte, puesto que el arte es la esencia de lo humano donde en el principio transcultural del ritmo preside el origen de la humanidad, puesto que la naturaleza del ser que es lo que fue y seguirá siendo como humano es la creación artística y la autocreación de humanidad a través del ritmo de las artes.

El ritmo se revela como el mediador, el sincronizador, el conector inconsciente, puesto que permite extender el cuerpo a la materialidad artística. El ser en ritmo vive una aventura que parte de la cotidianidad de su cultura hacia la acción extracotidiana que emerge cuando el artista actúa sobre 
la materia artística con su energía ritmada de los afectos fijados en su memoria biológica o corpórea que debe matizar los lenguajes artísticos con

Esto significa que el lazo mayor entre los seres humanos es el ritmo y desde que nacen siguen las pautas rítmicas que permearán todos los lenguajes expresivos para toda la vida.

\section{Aspectos de la escucha del ritmo}

No sabemos a dónde puede llevarnos la escucha del ritmo o de un ritmo en particular, pero debo señalar algunos aspectos de los procesos rítmicos como inductores de creación en todas las artes.

El primer aspecto del ritmo es su carácter pan-artístico. Pertenece a todas las artes y por esa razón puede convertirse en inductor de conexiones entre varios lenguajes. A partir del ritmo, el ser en ritmo trabaja la intertualidad entre diferentes registros sensibles de las materialidades artísticas que puede traducir en significantes de los lenguajes en diferentes artes: música traducida a cuerpo y a color y líneas que puede a su vez inducir el ritmo de imágenes o de las palabras. Siendo el ritmo pan-artístico, va más allá de un solo arte manteniendo la unión cenestésica de todos los órganos de los sentidos en sus conexiones más primitivas e inconscientes entre diversos órganos perceptivos. No hay un solo arte que pueda prescindir del ritmo que puede verse aunque no sea proferido en sonidos o en música. A través de él, del ritmo, nos topamos con un principio pre-expresivo y cenestésico cuyo eje esencial engloba el espacio corpóreo no sólo del cuerpo en las artes escénicas, sino que el ritmo marca la materialidad de todas las artes.

Más allá de los géneros, de los estilos, de las técnicas, de la consciencia, se encuentra ese ser en ritmo que para crear y existir en plenitud necesita del apoyo rítmico de su andar y de su voz, de entrar en ritmo, de sincronizar el lenguaje con su esencia íntima y personal de la existencia de un ser ritmado en su origen y que de allí deriva su originalidad como efecto emotivo fijado en los ritmos de los significantes de algún lenguaje para matizarlo. La lengua es un código de todos los hablantes, pero al ejercer el hablar el ser humano entrar a expresar su propio ritmo originario, su procedencia lingüística. El ser en ritmo puede sincronizarse a otros ritmos a partir de ser un ritmo humano que le permite comprender el ritmo de los otros y convertirse en escénico o musical o teatral o literario o pictórico según la matización que haga el sujeto del ritmo en el código expresivo cuando construye los textos en alguno de los lenguajes artísticos.

El segundo aspecto, derivado del primero, convierte el ritmo de pan-artístico en panhumano, un don de comunicación para interactuar con otros seres humanos de una misma cultura o de una cultura diferente. El origen de la humanidad se funda en naturaleza artística y poética como condición de la especie y sobre todo cuando el primer arte fue la danza rítmica apoyada por música 
corpórea de piés y manos, según los antropólogos, aunque luego surgieron las otras artes. Será necesario situar esa característica pan- artística de lo rítmico hacia un aspecto más general del origen de la humanidad con el impulso del ritmo como elemento sincronizador de los cuerpos, haciendo del ritmo el primer rasgo de una sincronía no solo fundante del arte de la danza sino de las culturas, tal como lo piensan las corrientes semióticas contemporáneas de la dimensión invisible (Edward T. Hall y otros) que dan prioridad a la comunicación cultural básica o primitiva, como organización orquestal o coreográfica de la vida

El tercer aspecto concierne el paso transformador del cuerpo biológico a la corporeidad cultural a través de la memoria corpórea o biológica sin representación que se fija energéticamente por ritmos corpóreos precoces en los tiempos de la época desde el nacimiento a épocas pre-verbales más avanzadas. Todavía el estadio del espejo cuando se fija la imagen inconsciente del cuerpo es una etapa rítmica. La corporeidad cultural se va construyendo como el punto de unión de lo físico, lo afectivo y lo mental y lo memorable corpóreo y visual permite el acceso de imágenes de una semiosis anterior al dominio de la lengua materna. Esa fijación corpovisual de ritmos puede orientar el arte hacia la expresión de algunos órganos perceptivos priorizados o lenguajes privilegiados que se han desarrollado precozmente a partir de la fijación significante de la representación de acontecimientos cuyo punto de contacto recorre el cuerpo, prioriza la memoria de algún órgano perceptivo, formando al mismo tiempo los procesos concretos sensibles de las artes y de las múltiples inteligencias. Apoyado en el ritmo inductor de imágenes, la primera inteligencia es corpórea y musical que permite pre-sujeto ser ritmo antes de ser sujeto hablante y consciente. El ritmo puede llegar a registros extraordinarios sensoriales más arcaicos, orgánicos y corpóreos de la memoria biológica, anterior a la memoria semántica que siendo más tardía depende del dominio de una lengua.

El verdadero bailarín, artista plástico o escritor necesita saber entrar en ese proceso inconsciente del ritmo inductor de la creación y saber salir de él. Salir hacia la consciencia más clarificada o más consciente y el espacio más expandido de sí mismo que esconde entre los significantes rítmicos una verdad personal, desde esa experiencia sensorial de las materialidades artísticas.

El cuarto aspecto sitúa el ritmo dentro de una categoría bio-antropológica del bios-artístico. Basado en lo que un antropólogo teatral llamó bios escénico, me permito extender ese concepto biológico a todos los bios de las artes, cambiando el calificativo del bios para llamarlo bios artístico, no solamente escénico donde el ritmo aparecería como organizador semiótico de la estructura más arcaica de la comunicación, la del cuerpo originario y de la prioridad de otorgar el desarrollo de la 
humanidad y de las inteligencias del sujeto a un aspecto bio-artístico con que se construyen las múltiples inteligencias a partir del lenguaje artístico que privilegia uno de los ritmos sensoriales en la distribución de las inteligencias a partir de una poética común a todas las artes que se corresponden con las múltiples inteligencias donde algunas se desarrollan más que otras. No solo de las artes sino de las ciencias se asientan en la memoria básica o primitiva de la escucha musical o rítmica. Así el autor de El oído y la música, Alfred Tomatis, tiene en su imaginario matricial un espacio originario y prenatal entre lo operático de la voz humana y la musicalidad de un instrumento: la escucha del piano y voz oído en su condición fetal desde antes de su nacimiento ${ }^{7}$. Ese ejemplo me hace preguntar hasta dónde llega biológicamente la memoria del cuerpo respecto a los ritmos escuchados no solo biológicos sino culturales.

El ritmo se eleva como la esencia del ser humano y de una poética común a todas las artes. Eso implica la interiorización corpórea de la medición de las percepciones sensibles primeras, el registro primitivo de un metro de las excitaciones perceptivas y del reposo, la medida de intervalos emocionales de apariciones y desapariciones de la escucha de los pasos en cercanía y lejanía, de la respiración, de los barridos de los órganos perceptivos.

El ser en ritmo del arte define una modalidad rítmica de origen: como el artista ha matizado, organizado, construido, desplazado los ritmos de su lenguaje hacia un espacio donde se juntan en su corporeidad lo biológicos y lo cultural, en significantes rítmicos que retienen los recuerdos de acontecimientos en una memoria corpórea o biológica, sin representación semántica ni lingüística, y que solo puede conocerse por el movimiento corpóreo o el desplazamiento del cuerpo a los ritmos de alguna materialidad artística.

\section{Conclusiones}

El ritmo es un elemento originario del ser humano, ontológico y filogenéticamente: el impulso rítmico es el primer elemento, primario e inconsciente, del origen de la construcción humana del sujeto como un puente entre el cuerpo biológico y la corporeidad cultural, entre el cuerpo y la lengua de la madre, entre los movimientos biológicos y las coreografías de la comunicación cultural o no verbal en cada cultura. A través del ritmo adviene el elemento esencial y originario de la inscripción del cuerpo biológico en el círculo de humanidad, a partir de una corporeidad que sigue con movimientos rítmicos la voz de la madre y luego al ritmo de las coreografías aprendidas de la comunicación cultural.

\footnotetext{
${ }^{7}$ Sobre este tema, ver: TOMATIS, Alfred, El oído y el lenguaje (1990), Hogar del libro, Barcelona. 
La sincronización del amor entre dos cuerpos, tan cercanos e íntimos desde el origen, prepara la adquisición de las coreografías culturales con que la corporeidad comunica con los afiliados a una misma cultura primaria o de la comunicación no verbal y con los hablantes de la lengua materna en la comunicación verbal. Y ese es el espacio humanizante que abre el ritmo en cada cuerpo: el paso del cuerpo biológico a la corporeidad cultural teñida de lenguajes y sincronizaciones rítmicas que caracterizan al ser humana. El ser en ritmo afirma el ser extremadamente humano que recuerda, con la memoria corpórea sin representación, el primer origen de su humanización inscrita a través del movimiento en las formas rítmicas.

Diríamos que la ritmicidad es el principio conector entre lo biológico y lo simbólico de la vida, entre el cuerpo materno de una voz que se convierte en movimiento rítmico del cuerpo energético del presujeto y, en el futuro, del sujeto que no se desprenderá de él y que sigue, sin ser consciente, el ritmo originario del ser o del somos desde el nacimiento. El cuerpo del recién nacido debe encontrar el ritmo para hacer el desplazamiento simbólico del hablar de la madre, ya oído en la matriz como un ritmo matricial, al cuerpo energético que, apenas nacido, debe ritmar sus movimientos con los acentos rítmicos vocales, desde los primeros días de nacido, al son de una lengua que oye como música con la que ingresará posteriormente a la coreografía de la comunicación cultural.

Ese primer ritmo escuchado, que permanece como significante sin representación, conectará siempre los ritmos del cuerpo que fuimos al que somos y seremos. El ser en ritmo sigue las latencias de sonidos acentuados en una voz materna pronunciando la lengua primera que nos baña con la cultura a la cual pertenecemos.

Partir de las determinaciones inconscientes de la humanización del ser humano que se construye autopoéticamente a través de principios rítmicos desde la dependencia con otro ser, emisor en ritmo cultural, pasa por esa fase de la escena de un traspaso único del escuchar el acento rítmico de la voz materna que se traslada a la inducción rítmica del movimiento autopoyético o autocreador poético del cuerpo.

Ser ritmo significa seguir un ritmo que fue una voz y luego estará en todos los lenguajes, desde el momento originario de nuestro nacimiento, en un cuerpo sin conciencia en búsqueda de la sincronización inicial con otros cuerpos que le hacen entrar en las partituras de la comunicación cultural y comprender el ritmo de los otros en la antesala en la génesis de la esencia humana, esa esencia rítmica que modela la sincronización en la interacciones con otros cuerpos y que perdurará en el sujeto. A través de la primera sincronía que modela la adquisición de la coreografía cultural con los ritmos de la partitura personal y la orquestación cultural ya interiorizada, el sujeto irá 
ordenando la sincronía del aprendizaje sonoro de una lengua. Y aquí podemos lanzar una pregunta final:

¿Qué puede decirnos el cuerpo? Mucho si observamos cómo se mueven las personas: si se mueven juntas o sincrónicas o si no. El tipo de ritmo con que se mueven, así como los acontecimientos pequeños, imperceptibles, que componen cualquier acción. (HALL, 1978, p. 68).

Y detrás de esos acontecimientos pequeños e imperceptibles, el artista encuentra el eje de un ritmo mayor en formas y palabras que forman su ser y que lo han conducido desde sus raíces culturales primeras a lo que es ahora, en el presente y lo que será en el futuro, entre el estilo individual y las coreografías culturales, entre el acento de un habla y los ritmos que acentúan la elaboración poética de los textos.

Todo lo cotidiano a fuerza del ritmo encontrado en el ser síncrono se transforma y retorna como el cuerpo glorioso de un adviento en los procesos artísticos, porque el arte no busca sino eso: un advenimiento simbólico de un cuerpo glorioso que resplandece bajo la magnificación y extrañamiento de un arte cuyas determinaciones responden a los ritmos originarios que han construido su cuerpo. Eso adviene al ser en ritmo: un ser que junta el ritmo de su ser actual al ritmo que le advino en los significantes de su origen de un recuerdo infantil guardado como primeras marcas humanizantes en la memoria sin representación de la época pre verbal.

Y quisiera cerrar soñando una ciencia compleja que investigue la presencia de lo viviente en los ritmos que mantienen los trazos del origen del ser humano, en ese puente tendido en el ser en ritmo entre el arte y la vida:

Una ciencia de la presencia de lo viviente, una disciplina consagrada a la descripción de comportamientos emergentes fundadores de la identidad no tiene solamente un valor de erudición. Ella introduce el descubrimiento de lo múltiple en la unidad de la especie, de lo sutil en la diversidad, en lo más profundo del enigma de la vida y de su respeto amoroso. (PRADIER, 1996).

El ritmo podría ser eso que el etnoescenólogo francés Jean-Marie Pradier designa como lo que nos lleva al profundo enigma de la vida y de su respeto amoroso. Es algo semejante a lo que dice el exergo inicial, cita del Diccionario de Autoridades, con que abrí la presente exposición donde el ritmo es la interpretación del amor que hace del artista un intérprete del lenguaje amoroso.

Y eso cierra la pregunta del comienzo: lo que adviene a través del ser en ritmo es la forma del amor y del misterio de la vida a través del arte que trae el afecto originario del primer contacto del cuerpo naciente con otro que lo ha engendrado y que lo envuelve de sonidos y afectos al ritmo de una lengua musical que nos humaniza. 


\section{REFERENCIAS}

BOULTON, Alfredo (1979). Reverón, Ediciones Macanao y Alfredo Boulton, Caracas.

BOULTON, Alfredo (1966). La obra de Armando Reverón, Ediciones de la Fundación Neumann, Caracas.

ELDERFIELD, John (2007). "La historia natural de Armando Reverón”, en: Armando Reverón, The Museum of Modern Art, Nueva York y Proyecto Armando Reverón /Caracas),

FUENMAYOR, Víctor y LUCKERT, Fanny (2008). Ser cuerpo. Ser música. Didáctica del ser creativo, Universidad del Zulia, Ediciones del Vice-Rectorado Académico, Maracaibo.

FUENMAYOR, Víctor (1998). Materia, cripta y lectura de Horacio Quiroga, Universidad del Zulia, Vice-rectorado Académico, Maracaibo.

FUENMAYOR, Víctor (1999). El cuerpo de la obra, Instituto de Investigaciones Literarias y Lingüísticas, Facultad de Humanidades y Educación, Universidad del Zulia, Maracaibo.

HALL, Edward T. (1978). Más allá de la cultura, Editorial Gustavo Gili, Barcelona.

JACOBSON, Roman (1981). Lingüística y poética, Ediciones Cátedra, Madrid.

KRISTEVA, Julia (1974). La révolution du langage poétique, Seuil, Paris.

LACAN, Jacques (1966). Ecrits, Seuil, Paris.

PRADIER, Jean Marie (1996). "Ethnoscénologie: la profondeur des emergences", en DUVIGNAUD, Jean, ROUGET, Gilbert, y otros, La scene et la_terre, Questions d'ethnoscénologie, Babel, Maison des cultures du monde, Paris.

STAROBINSKI, Jean (1971). Les mots sous les mots. Les anagrammes de Ferdinand de Saussure. Gallimard, Paris.

TAPIES, Antoni (1971). La pratique de l'art, Editions Gallimard, Paris.

TOMATIS, Alfred (1969). El oído y el lenguaje, Ediciones Martínez Roca, Barcelona. 